\title{
GENDER BASED BARRIERS IN ACCESSING TUBERCULOSIS TREATMENT: A QUALITATIVE STUDY FROM EASTERN NEPAL
}

\author{
Kumar G, Jha N, Niraula SR, Yadav DK, Bhattarai S, Pokharel PK \\ School of Public Health and Community Medicine, B. P. Koirala Institute of Health Sciences, Dharan, Nepal
}

\begin{abstract}
Introduction: Previous studies have demonstrated longer length of delays in diagnosis and treatment among men and women, especially among women experiencing longer duration of delay in accessing tuberculosis treatment. So, the study was conducted to explore responsible factors among men and women affecting longer duration in accessing tuberculosis treatment.

Methodology: Qualitative approach with FGD sessions among people from community, DOTS providers and pulmonary tuberculosis patients were conducted separately in between March 2012 to May 2012.

Results: The perception of fear, hiding symptoms, social stigmas and traditional beliefs were common among women. The study revealed that social and cultural barrier, ignorance of symptoms, home remedies, fear of stigma, access to health centre from rural areas, poor knowledge of TB signs and symptoms, beliefs on traditional healers were the common reason for the longer delays in diagnosis.
\end{abstract}

Conclusions: The findings suggested that knowledge, information, perception regarding TB among men and women were lacking, especially among females. This warrants awareness for early diagnosis and control of disease.

Key words: Delay, Gender, Nepal, Tuberculosis

\section{INTRODUCTION}

Gender refers to "the socially constructed roles, behaviours, activities and attributes that a given society considers appropriate for men and women". ' Globally, reported TB (Tuberculosis) is more common among men than women and affects mostly adults in the economically productive age group of $15-59$ years. ${ }^{2,3}$ Though the morbidity pattern is more among males but it kills more women in reproductive age group making it the

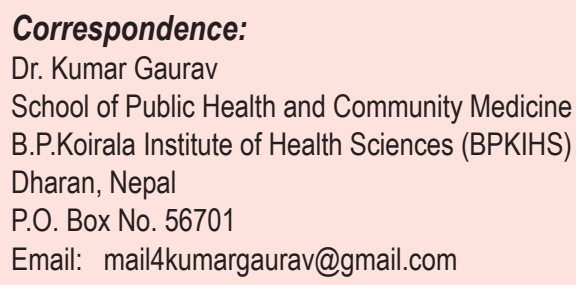

third leading cause of death among women of age group 15 - 44 yeas. ${ }^{4}$ National TB programmes across different countries reporting high morbidity pattern of male cases may accurately reflect a greater prevalence among men, or it may be an artefact of persisting geographic, socioeconomic, cultural, and health service - related barriers that disproportionately affect timely diagnosis and treatment in women. Early diagnosis and effective DOTS strategy form the key elements of TB control programme. ${ }^{2,3}$ In Nepal, DOTS have been expanded to1118 treatment centres and 3103 sub centres throughout the country. ${ }^{5}$ Even though, women reach to the DOTS centre through various multiple channels than men. Study from western Nepal reported patients' intricate routes starting with medical shop and various multiple providers before reaching to qualified health provider. ${ }^{6}$ This delay in diagnosis may lead to disease presentation at more advanced stage contributing to late sequel 
and mortality. Previous studies ${ }^{7}$ have defined such delays can occur at different level and majority have reported diagnosis delay between 60 and 90 days. Studies from Nepal, India, Bangladesh and from African countries had documented longer duration of delay period in accessing TB treatment among women than men. ${ }^{7}$ In poor countries, men has not as much barriers as women has to face due to less financial resource and weak decision power. ${ }^{8}$ As per individual perspective, healthcare seeking behaviour has different dimension which lands on individual's perception regarding disease and its severity, socioeconomic and socio cultural factors, extent of awareness, accessibility to health services and treatment action. So, the clear understanding of barriers in accessing TB services, especially among women is needed for the control of the disease.

\section{METHODOLOGY}

\section{Study design}

It was a qualitative study. A qualitative research - Focus Group Discussion (FGD) technique was used which involved use of in depth group discussion on gender difference to assess the gender related behaviours and attitudes towards TB and related stigmas in accessing TB treatment that results in delay of diagnosis and treatment. The FGD sessions were conducted at three selected teaching districts (Sunsari, Morang, Dhankuta) of B.P. Koirala Institute of Health Sciences between March 2012 to May 2012 in eastern Nepal. A total of three FGD sessions were carried out separately at Dhankuta, Morang and Sunsari district among three distinct groups. Participants of each group were purposive representative sample of specific population. Each FGD session consisted of 1012 participants that included males and females together for the in depth group discussion. Separate guidelines were developed for each session.

The first session was conducted among community people (with no history of TB) at Dhankuta with the help of DOTS in charge and FCHV (female community health volunteer) at the community level. The FCHVs were included to get in depth perception regarding TB among locals. The second session was carried out among TB patients (sputum positive and negative cases under DOTS) in Morang district at NATA (Nepal Anti Tuberculosis
Association) DOTS centre Biratnagar. In each FGD above, with regard to gender homogeneity, we tried to maintain gender balance by active participation from males and females. The participants were made ease to share their experience, opinions, beliefs and suggestions on the issues of gender difference in general health seeking behaviour, knowledge, perception regarding TB and TB related stigmas, gender role in family and accessing health services for treatment. The third session was conducted at Dharan (Sunsari district) with DOTS providers (giving TB medicine on regular basis at their respected centre) to take views regarding the behavioural aspect and perception regarding TB among TB patients (men and women) coming to DOTS centre for medication. The sessions effectively brought feelings, ideas, opinions, views and beliefs from the free flowing discussion between moderators and respondents. It was helpful in getting the views and opinions of women's behavioural nature and their approach towards health. Participants for FGD were included as per their interest in taking part in discussion and were allowed to withdraw at any time. Less than 15 years of age were not included in discussion. The study protocol was approved by BPKIHS institutional ethical review board.

\section{Data analysis}

The FGD sessions were conducted and facilitated by principal investigator along with co-investigators as experts to prepare reports. The three FGDs conducted at different level were tape recorded and analysed directly after the session using thematic framework analysis. ${ }^{9}$ The thematic framework was constructed after proper familiarization with data by listening to the tapes several times, writing transcripts by hand, indexing and charting of the highlighted quotes from different FGD sessions and finally appropriate themes were constructed through developed pattern. The data was interpreted through actual words used and meaning, context consideration, frequency and intensity of comments and internal consistency.

\section{RESULTS}

\section{Knowledge and health seeking behaviour}

FGD conducted at community level expressed their views as they had heard of TB but they do not have 
knowledge regarding TB which creates negligence in treatment seeking. For the initial symptoms, visit to other several places was common practice rather than visiting hospital or health facility centre. This included visit to pharmacy, traditional healers, private practitioners and self medication practice. When the symptoms got worse after that only they start willing to go tertiary facility centre. One of the male participants expressed his feeling as "I work outside and earn money day to day for the living of my family. If we get some type of illness we initially wait for some day to heal and try local home remedies. In our area, we still go to traditional healers for the treatment. The reason is economical constraints, and the hospitals, private centre are so expensive that we have to think twice to go there contrary to traditional healers which are comparatively very cheaper".

Participants indicated that women were more reluctant to spend money or to access modern health services for their own need. So, they were much associated with local medications or traditional beliefs secretly until the symptoms aggravate. Even after that they used to or try to hide the symptoms with a fear to get diagnosed with some disease. A male community volunteer expressed his feeling as "Women are much concerned about their family irrespective of their ill health if present. She does not have time for herself, but for family and children she has time and first one to take step forward. The husband and children always come first for her."

FGD conducted among TB patients revealed that unawareness of the symptoms recognition and negligence among women (more) and men were the delay factors for diagnosis and treatment initiation among. The presence of cough was merely a feeling of minor infection which could heal by itself. The practice of self medication and visit to drug store was common. One of the female TB patients says, "I was having cough and chest pain for long time but I did not take care of that, as I thought it is due to the work load at home that am not taking care of. I visited local drug stores for medicine as it is cheap and symptoms were relieving after taking that medicine but again used to start after leaving medication for some days. Then my family member and my husband counselled and advised me to visit district hospital for the problem".
The hospital/health centre shopping was another reason found to be in delays among TB patients. If at one centre they did not get relief for a week, they made move to another consultation either private or public centres. Thus, want of quick diagnosis and treatment at higher centres create a dilemma of wrong perceptions of tertiary level.

When asked about the cause and types of TB in FGDs among TB patients and community volunteer, they said "yo fokso ma lagney rog ho jasto (nepali)" "it is like disease of chest" but had no information on types of TB disease, its severity and occurrence but had the perception that heavy works, alcoholism, smoking or contact from others having similar illness can lead to the TB disease. The discussion concluded that people do not have the health seeking behaviour as they lack health information about symptoms and severity of tuberculosis.

According to the DOTS providers, women were much shy and hesitant to express their problem in family which gives the negative effect on their health care seeking behaviour. Even when they reach the health centre, they used to feel shy and ashamed of telling their symptoms of coughing blood. Actually they did not want to share it as they were having greater fear of TB associated stigmas.

\section{Perception regarding TB and TB related stigmas}

Discussing on, as men are diagnosed more commonly than women, view came out from community and TB participants as men work outside and do heavy works which affect their health status but women are confined to house work only so they were not exposed to the outer world. DOTS provider stated that females could not present their illness as strongly as males due to poor health awareness or limited access to the health centres. One of DOTS provider says "The knowledge regarding TB transmission is not well oriented. So, the disease continues to run in the family and is transmitted from one person to another and subsequently to surroundings".

The fear of diagnosis or social isolation was not seen among males during FGDs among community volunteer and TB patients but inconvenience to sit with other or work and marriage difficulties were the issues that were raised. Men, being bread earners 
in the family and if gets infected with disease, had fear of loss of job which creates a huge responsibility on them for the family. Participants focused that females usually used to hide the symptoms or any illness present until and unless it aggravates to its much severe condition. It was the serious matter among women in delay in accessing health services due to the perception of fear of social isolation, affect in family relations or marital relations. Participants from community stated that knowing about the illness they usually did not take care for that or try to hide as married females has the priority for her family and unmarried had feeling of being get ashamed in the society. Regarding marriage problem, one male community participant told that "When he was in his village, he saw marriage proposal being rejected by female when they came to know that man is having TB. She did not want to marry a TB patient". So it is not the case with females only, males had an equal fear for that and had tendency to hide the disease.

Discussion with DOTS providers they felt that TB stigmas were still present in the community giving the negative perceptions in treatment seeking. DOTS providers stated that females used to ask to give medicine for a week or more as they did not want to come daily to the DOTS centre as they feel fear of getting recognised by some known person in the community. This tendency was commonly seen among unmarried girls as a reason for marital difficulties due to illness. The tendency of hiding the disease was seen less among males as they are not reluctant as females to share their symptoms and discuss their problems with others.

From the discussions it was ruled out that women in the society mostly in the rural areas are more stigmatized than males in treatment seeking and these types of behavioural pattern norms the delays in accessing treatment.

\section{Gender role in the family}

Communicating with community and TB participants, informant felt that in urban areas the views are changing as women are able to take decision by their own but at rural area, women are still dependent on their family. Female participants felt that men are the building block of the family, independent, socially active for accessing resources. One female TB patient expressed her feeling as "Men are bread winner for family; his health is first to me and to be taken care of". Women were mostly dependent on their family and have limited resources, education and knowledge to access health services. One of the FCHV volunteer said that "females tend to hide the symptoms as they are sometimes not the decision makers in the family and need to take permission to go out for health check up. Before they decide to seek care, first is to recognise the symptoms or to develop health seeking behaviour among them."

The gender difference characterization such as men easily discuss their illness or other health problems among family members and decision making permits them to cut the delays, whereas shyness or hesitancy among women has made them weak to share their problem in family, and lack of health information and decision making power trigger the delays in diagnosis and treatment among them.

\section{Suggestions from participants}

Participants felt that symptom recognition, awareness about ill effects of TB should be promoted and disseminated more in rural areas. To combat the running stigmas among men and women, they expressed that social support is needed from family members, relatives, and friends. Women participation should be encouraged at the ground level and information should be discussed in more lay man and local languages with examples or pictorial display.

\section{DISCUSSION}

Focus group discussions in this study revealed that the presence of low knowledge, lack of awareness regarding TB severity and weak financial status make people to visit traditional healers or practice self medication from pharmacy which are comparatively cheaper and easily accessible than hospital. Qualitative results from western Nepal ${ }^{6}$ and Gambia ${ }^{10}$ also reported that visit to pharmacies and traditional healer as first choice. This negligence of treatment seeking among men and more among women creates the denial and concealment behaviour where they hope that symptoms will go away on their own which in turn gradually increases the severity of disease. Hence, the delay in diagnosis at advanced stage leads to increase in the number 
of mortalities. A study from Tanzania ${ }^{11}$ found that patients with low knowledge were more likely to visit traditional healer and pharmacies, similar to our findings of negligence and postponing health seeking treatment. The perception of fear, hiding symptoms, social stigmas and traditional beliefs were common among women. Qualitative findings from India ${ }^{12}$ also reported fear of social stigmas, ignorance of symptoms, home remedies as factors for delay in accessing to health centres. Not only the individuals but also the whole family may suffer from social stigma and its negative consequences, which are harsher for the female family members. Stigma may lead to delays for both sexes in seeking care, but more so for females if the physical, geographical, and economic access to healthcare is limited which is more in context of developing countries. Females can delay longer for a number of reasons, for example not having the authoritative powers in the household, being dependent on their husbands both economically and on social issues and repressed to discuss any ill health with their family with fear of social isolation. Studies ${ }^{13}$ had shown that fear of social isolation from family or community is a key factor contributing to delay among women. These factors have made women socially dependent, fragile and dominated by others that influence their minimal role in decision making power in family and access to health centres for care seeking. Our above findings in the assessment of factors in accessing treatment after onset of symptoms brought important point that lack of continuing TB education, especially among private pharmacies, traditional healers, quacks, self medication practices, contribute to poor knowledge among them and therefore poor ability to recognise symptoms and suspect TB leading to reach the health centre at late stage and contributing longer delay in diagnosis. Moreover, women often ignore or hide the disease for fear of divorce or abandonment. It is imperative to improve and implement appropriate health education on TB symptoms, diagnosis, curability, and social stigma for the entire population, as well as health providers at any level, in order to reduce diagnosis delay and fear.

\section{CONCLUSION}

The knowledge, information, perceptions regarding TB among men and women were lacking, especially among females creating negligence in treatment seeking. The information regarding TB should be disseminated to more remote areas and every effort should be made to increase women empowerment in living, decision making and developing health seeking behaviour to alleviate barriers in accessing treatment. Effective programmes like ACSM (advocacy, communication and social mobilization) by NTP can raise public awareness of the disease and treatment, address misconceptions about TB and create demand for DOTS. For the control of the disease early diagnosis is important.

\section{ACKNOWLEDGEMENT}

I would like to thank faculties and resident doctors of School of Public Health and Community Medicine for their support in study period and DOTS in charges for their co-operation in conducting discussion sessions at respected centres.

\section{REFERENCES}

1. Thorson A. Tuberculosis and Gender. Denmark: WHO European Ministerial Forum; 2007 Sep (EUR/TB/FS05).

2. World Health Organization report 2011. Global tuberculosis control. Geneva: World Health Organization; 2011 (WHO/HTM/TB/2011.16).

3. Harries A, Maher D, Uplekar M. National Tuberculosis Programme of Nepal-A clinical manual. Bhaktpur: National tuberculosis centre (Nepal); 2009.

4. World health organization report 2009. Women and tuberculosis. Online, WHO. Accessed 19 May 2012 <http://www.who.int/tb/challenges/gender/ women_and_tb/en/index.html.>

5. Department of health services annual report 2010/2011. Kathmandu. Ministry of Health and Population (Nepal); 2012 Feb.

6. Asbrek A, Bijlsma MW, Malla P, Shrestha B, Delnoij DMJ. The road to tuberculosis treatment in rural Nepal: A qualitative assessment of 26 journeys. BMC Health Service Research. 2008;11:8-7.

7. Tesana $\mathrm{N}$ and Butsorn A. Delay in diagnosis and treatment of Pulmonary Tuberculosis between 1987 and 2007: literature review. Thai Journal of Tuberculosis Chest diseases and Critical care. 2008;80-102. 
8. United Nations Entity for Gender Equality and the Empowerment of Women. United Nations. UN Women; 2011. Online, accessed on 19 May 2012 <http://www.unifem.org/gender_issues/women_ poverty_economics/

9. Rabiee F. Focus group interview data analysis. Proceedings of the Nutrition Society. 2004;63:65560.

10. Eastwood SV and Hill PC. A gender focused qualitative study of barriers to accessing tuberculosis treatment in the Gambia, West Africa. INT J TUBERC LUNG DIS. 2004;8:70-75.
11. Verhagen LM, Kapinga R, Nooijens KAWL. Factors underlying diagnostic delay in tuberculosis patients in a rural area in Tanzania: A qualitative approach. Infection. 2010;38:433-46.

12. Bawankule S, Gaidhane A, Khatib N. Delay in DOTS for new pulmonary tuberculosis patients from rural area of Wardha District, India. Online Journal of health and allied Sciences.2010 JanMar; Vol.9.

13. Waisbord S. Behavioral barriers in tuberculosis control: A literature review (Internet). The CHANGE Project/Academy for Educational Development. Available from: http: // pdf.usaid.gov/pdf_docs/ Pnadf406.pdf. 